\title{
An Exploration of Burn Survivors' Experiences of Pressure Garment Therapy at a tertiary hospital in South Africa
}

\author{
Rogini Pillay, B Sc Occupational therapy (UCT); Mphil (Rehabilitation) (US) \\ Assistant Director: Occupational Therapy, Groote Schuur Hospital, Cape Town
}

Surona Visagie, B Sc Physiotherapy (US); MSc and Phd (Health Sciences) (US)

Post-doctoral fellow, Centre for Rehabilitation Studies, University of Stellenbosch

Gubela Mji, Bsc Physiotherapy Medunsa, HED UNISA, MSc UCT, PhD (UCT)
Director, Stellenbosch University, Centre for Rehabilitation Studies, University of Stellenbosch

Introduction: Pressure garment therapy is used to treat hypertrophic scars, but adherence to this intervention presents challenges. The aim of the paper was to explore the pressure garment therapy experiences of adult burn survivors.

Methods: The experiences of eight purposively sampled participants were explored in a qualitative, phenomenological study. Data were collected by means of semi-structured interviews. Thematic analysis was conducted.

Results: Participants described an improvement in the scars, but struggled with adherence to pressure garment therapy. The emotional impact of the burn injury, physical symptoms, the effort of caring for the garments and aesthetic factors created barriers to adherence. Support, inner strength, knowledge, and seeing an improvement facilitated adherence.

Conclusion: The findings of the study show that participants perceived pressure garment therapy as beneficial, but several complex factors impacted adherence. A bigger choice in material colours, a person-centred approach to burn management, digital photos of scars to catalogue improvement and the establishment of a counselling network are recommended.

Keywords: Burns, hypertrophic scars, pressure garment therapy, adherence

\section{INTRODUCTION}

Maclntyre et al' concluded in a systematic review on the effectiveness of pressure garment therapy (PGT) in 2005 that while PGT seems to reduce scar formation, improve scar appearance, decrease itchiness, pain and contractures, the effect of this therapy remains inconclusive. This was confirmed in 2012 through a survey of American occupational therapists, who agreed with the findings on improved appearance (85\%), contractures/movement (7I\%) and a reduction of itchiness $(65 \%)^{2}$. Anzarut et $\mathrm{al}^{3}$ and Szabo et $\mathrm{al}^{4}$ agreed that the effectiveness of PGT has not been firmly established.

The use of a randomised control trial to establish the effectiveness of PGT in a setting where the treatment modality is accepted as the most appropriate, could be viewed as unethical. Such randomised control trials are further hampered by a lack of gold standard scar assessment tools. The Vancouver Scar Assessment Scale (VSS) - the most frequently used tool to assess scar characteristics - is purported to be unreliable, and is criticised because scoring is based on a subjective clinical assessment and scores depend on the opinions and skills of clinicians $s^{5,6,7}$.

Qualitative research is not dependent on opinions and skills of health care providers, but garners valuable information on the perspectives of burn survivors, the very persons who are the benficieries of the service. Yohannan et $\mathrm{al}^{2}$ regard these recipients of health care services as an untapped resource in burn rehabilitation research. Their perspectives can assist in addressing the inconclusive evidence for the effectiveness of PGT. This paper aims to add to the evidence provided by three qualitative studies on adults 'experiences of scar management. through exploring Capetonian burn survivors' experiences of PGT. The other studies on patients' experience with PGT that were identified included a phenomenological study from the United Kingdom by Martin and colleagues ${ }^{8}$, a South African study by Stewart et al ${ }^{9}$ and a German study (2009) by Ripper et al ${ }^{10}$, that - as in the current study - used the Health Action Process Approach (HAPA) as framework.

\section{LITERATURE REVIEW}

Hypertrophic scarring is a common consequence of burn injuries. Literature reviews by Esselman et $\mathrm{al}^{5}$ and Bloemen et $\mathrm{al}^{6}$, both of which included studies from as early as 1990, showed large variance (30-90\%) in the prevalence of hypertrophic scarring after burns. Studies performed after 2000 show greater similarity with a $5 \%$ variance in prevalence. In these studies the lowest prevalence was $67 \%$ in an American study 1 and the highest was $72 \%$ in an Italian study ${ }^{12}$.

Hypertrophic scarring is associated with high levels of morbidity

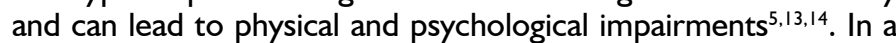
synthesis of qualitative research, Kornhaber and colleagues ${ }^{14}$ provide vivid narratives in which burn survivors explore and explain the physical, psychological and social impacts of scarring, which include pain, loss of range of movement, changed body image, depression and social stigmatisation.

A review of the literature confirmed that PGT is one of the most common treatment modalities used in the prevention of hypertrophic scarring $5,7,11,15$, however, is not without challenges. Literature reviews indicate that PGT is a time consuming, expensive and demanding regime $1,5,6,7,11,13,16$. Treatment recommendations for optimal outcomes require that the garments are worn 23 hours per day and provide consistent and adequate pressure until scar maturation is attained, usually after 12-24 months $s^{1,5,6,13,16}$. This requires patience and motivation as changes in the appearance of scars are slow and improvements are only noted through careful observation ${ }^{7}$.

As indicated by Yohannan et $\mathrm{al}^{2}$ patients reported positive results in terms of scar appearance and mobility after PGT even though they found them uncomfortable and were reluctant to wear the garments outside their homes. Martin and colleagues ${ }^{8}$ provide valuable insight into the duality of patients' responses to 
PGT in their exploration of the lived experiences of eight people in the United Kingdom. The participants compared the familiarity of pressure garments to a comfort blanket, and the rigours associated with the regime of wearing them to a straight jacket. These factors affect adherence to the wearing of the pressure gartments.

A review of seven studies on patient adherence to PGT from settings as diverse as South Africa, Saudi Arabia, Taiwan, Germany and America found that adherence varied from $15.3 \%$ in a setting with no dedicated burn care to $81.3 \%$ in a setting that provided dedicated burn care ${ }^{4}$. Of particular interest is the research by Stewart et $\mathrm{al}^{9}$ who conducted a small-scale descriptive analysis, much like the current one, on the factors affecting pressure garment adherence in South Africa. They found that $41 \%$ of their participants were fully adherent to PGT and that health behaviour and relationships with service providers played a major role in non-adherence to PGT.

Patient non-adherence is a complex phenomenon. The Health Access Process Approach (HAPA) model (Figure I) has been used previously to assess adherence in $\mathrm{PGT}^{10}$ and provides a framework to describe changes in health behaviour. The HAPA is premised on on two phases: a motivational and a volitional phase ${ }^{10,17}$. The motivational phase is dependent on the patient's intention to initiate adherence whilst the volitional phase involves translating this intent into action.

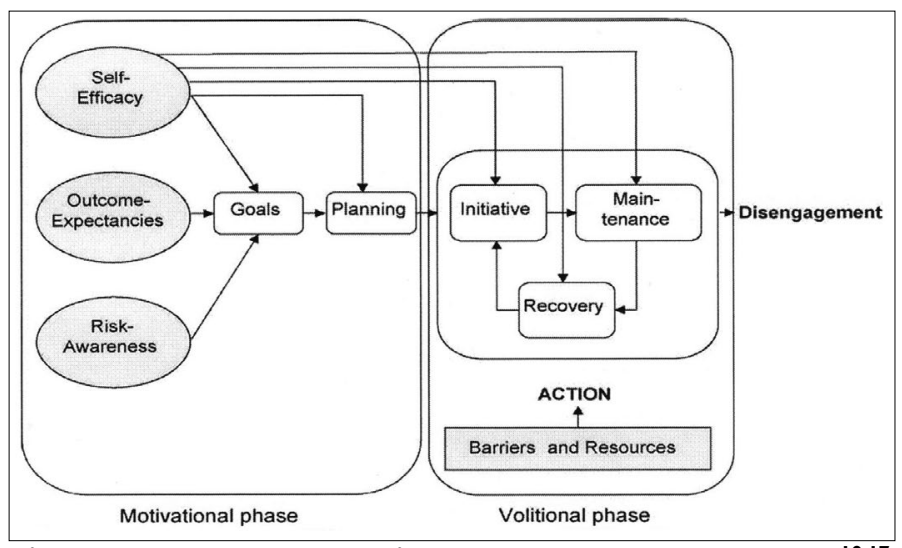

Figure I: The Health Action Process Approach Model ${ }^{10,17}$

The motivational phase is contingent with the person's belief about what he/she is capable of doing (self-efficacy), expected outcomes and to a lesser extent, risk awareness when embarking on $\mathrm{PGT}^{17}$. In the volitional phase (actual wearing or not wearing the PGs) the change must be "planned, initiated, and maintained, and relapses must be managed" 17:4. The volitional process contains action and coping plans and is strongly influenced by perceived self-efficacy as well as perceived barriers and resources ${ }^{17}$.

\section{METHODOLOGY}

A qualitative, phenomenological design was used to allow participants to share their views and experiences. Study participants received $P G T$ at the occupational therapy department of a tertiary hospital in Cape Town, South Africa, which hosts a specialist burns unit. Pressure garment therapy, provided by the occupational therapy department, comprises a large component of scar management at this unit.

The 179 patients, who received PGT between 2006 and 2010 at the study hospital constituted the study population. Participants had to be older than 17, without cognitive impairments and residing in the Western Cape metro health district. Following a purposiveness approach the primary author, an occupational therapist who provided PGT at the burns unit, used her personal knowledge of the patients to select those whom she thought would be able to provide detailed, nuanced information ${ }^{18}$. In order to explore the topic as widely as possible a hetrogenous sample including men and women, from various age groups, socio economic and cultural backgrounds, with varying percentages of total body surface area burnt and in need of various garments was selected. Data saturation was reached after the eighth interview and data collection was terminated at this point.

An interview schedule, based on the primary author's clinical experience, the HAPA and information drawn from literature ${ }^{7,9,10}$ was used to guide data collection. The following aspects relevant to this paper were covered in the interview schedule:

* How did you experience the PGT service and wearing the PG?

* What helped or hindered you in wearing the PG?

* What changes could be made to PGT service?

Whilst aware of the advantages of performing interviews personally, to prevent bias the primary author and service provider to participants, opted not to conduct the interviews. An occupational therapist experienced in conducting qualitative research, and familiar with PGT performed the interviews in a private room at the occupational therapy department or the participants' homes, depending on their preference. Interviews were audio recorded. After completion of each interview the primary author discussed it with the interviewer and allowed her to reflect and debrief. The primary author transcribed each interview as it was completed and did a preliminary analysis of the data. The preliminary analysis showed data saturation after the eighth interview. Although most participants were isiXhosa-speaking, they opted to be interviewed in English.

Content analysis was done. Codes that recurred were formed into categories and these merged into themes that were related to the study objectives. Narrative examples are provided in the results to illustrate the themes ${ }^{18}$.

\section{Ethical Considerations}

The study was registered with the committee for Human Research at Stellenbosch University. Permission was obtained from the Chief Executive Officer of the study hospital. Participation was voluntary and written informed consent was obtained before data collection commenced. This included consent to use a tape recorder. Pseudonyms were used to identify participants and to maintain confidentiality. Participants who showed signs of emotional trauma during the interview were offered followup counselling sessions with an occupational therapist or social worker.

\section{Rigour}

In an effort to ensure credibility the interviewer verified the researcher's transcriptions of the recorded interviews. Telephonic contact was made with four of the participants to check if the analysed data correctly summarised their experiences. The questions were piloted with two burn victims to determine whether the information yielded answered the aim and objectives of the study. Where opposing opinions were voiced both were included. Rich data based on participants' lived experiences were collected and narrative examples were provided in the transcript. A data base was maintained, to allow an audit or independent analysis. This also made it possible to assess credibility, consistency and neutrality. While the findings are not generalisable to the larger population or other populations due to a small, unrepresentative and non-uniform sample, the context and methods were described in detail should anyone want to determine if findings and recommendations can be transferred to a different context.

\section{RESULTS}

Table I on page 75 provides demographic information, burn history and adherence to PGT of participants. Four participants sustained partial thickness burns and four full and partial thickness burns ranging from $5-30 \%$ total body surface area. 
Table I: Demographic and burn information

\begin{tabular}{|c|c|c|c|c|c|c|c|}
\hline & Age \& Gender & Race & \%TBSA & Depth of burn & $\begin{array}{l}\text { Body parts } \\
\text { involved }\end{array}$ & $\begin{array}{l}\text { Type of } \\
\text { garments }\end{array}$ & Adherence \\
\hline Andiswa & $22 ; \mathrm{F}$ & African & $10 \%$ & $\begin{array}{l}\text { Superficial \& } \\
\text { deep partial } \\
\text { thickness }\end{array}$ & $\begin{array}{l}\text { Shoulder, thumb } \\
\text { \& foot, Donor } \\
\text { area: thighs }\end{array}$ & $\begin{array}{l}\text { Sleeve, mitten \& } \\
\text { sock }\end{array}$ & $\begin{array}{l}\text { Poor } \\
\text { Did not complete } \\
\text { therapy }\end{array}$ \\
\hline Ann & 79; F & White & $15 \%$ & $\begin{array}{l}\text { Deep partial } \\
\text { thickness }\end{array}$ & $\begin{array}{l}\text { Both feet Donor } \\
\text { area: thighs }\end{array}$ & Knee high socks & $\begin{array}{l}\text { Good } \\
\text { Completed therapy }\end{array}$ \\
\hline Bongani & $49 ; M$ & African & $20 \%$ & $\begin{array}{l}\text { Deep partial \& } \\
\text { full thickness }\end{array}$ & $\begin{array}{l}\text { Feet, legs, Donor } \\
\text { area; thighs }\end{array}$ & $\begin{array}{l}\text { Long Pants \& } \\
\text { socks }\end{array}$ & $\begin{array}{l}\text { Good } \\
\text { In therapy at time of } \\
\text { interview }\end{array}$ \\
\hline Fleur & $22 ; \mathrm{F}$ & White & $6 \%$ & $\begin{array}{l}\text { Deep partial } \\
\text { thickness }\end{array}$ & $\begin{array}{l}\text { Thigh, Donor } \\
\text { area: thigh }\end{array}$ & Short pants & $\begin{array}{l}\text { Good } \\
\text { In therapy at time of } \\
\text { interview }\end{array}$ \\
\hline John & $21 ; M$ & Coloured & $25 \%$ & $\begin{array}{l}\text { Deep \& full } \\
\text { thickness burns }\end{array}$ & $\begin{array}{l}\text { Face, head, torso, } \\
\text { arms \& hands, } \\
\text { Donor area: back } \\
\text { \& thighs }\end{array}$ & $\begin{array}{l}\text { Short pants, } \\
\text { jacket, mittens, } \\
\text { mask \& } \\
\text { chinstrap }\end{array}$ & $\begin{array}{l}\text { Average. Completed } \\
\text { therapy }\end{array}$ \\
\hline Mandy & $20 ; \mathrm{F}$ & Coloured & $10 \%$ & $\begin{array}{l}\text { Superficial \& } \\
\text { deep partial } \\
\text { thickness }\end{array}$ & $\begin{array}{l}\text { Chest, arm face \& } \\
\text { ear, Donor area: } \\
\text { thighs }\end{array}$ & $\begin{array}{l}\text { Short pants \& } \\
\text { jacket }\end{array}$ & $\begin{array}{l}\text { Poor initially, } \\
\text { improved after scars } \\
\text { became raised. } \\
\text { In therapy at time of } \\
\text { interview }\end{array}$ \\
\hline Phindi & $27 ; F$ & African & $27 \%$ & $\begin{array}{l}\text { Superficial, partial } \\
\text { \& full, thickness }\end{array}$ & $\begin{array}{l}\text { Legs \& feet, } \\
\text { Donor area: } \\
\text { thighs }\end{array}$ & $\begin{array}{l}\text { Long pants \& } \\
\text { socks }\end{array}$ & $\begin{array}{l}\text { Good } \\
\text { In therapy at time of } \\
\text { interview }\end{array}$ \\
\hline Sipho & $36 ; M$ & African & $30 \%$ & $\begin{array}{l}\text { Deep partial \& } \\
\text { full thickness }\end{array}$ & $\begin{array}{l}\text { Hands, arm \& } \\
\text { back, Donor area: } \\
\text { thighs }\end{array}$ & $\begin{array}{l}\text { Sleeves \& } \\
\text { mittens }\end{array}$ & $\begin{array}{l}\text { Good } \\
\text { Completed therapy }\end{array}$ \\
\hline
\end{tabular}

Table II: Categories under the two main themes according to HAPA components

\begin{tabular}{|c|c|c|c|c|}
\hline & Self efficacy & Risk awareness & Outcome expectations & Resources and barriers \\
\hline $\begin{array}{l}\text { Definition according to } \\
\text { HAPA }\end{array}$ & $\begin{array}{l}\text { Believing yourself capable } \\
\text { of performing the activities } \\
\text { required to achieve the } \\
\text { desired outcome }\end{array}$ & $\begin{array}{l}\text { Knowledge of the negative } \\
\text { outcomes that may result } \\
\text { from non adherence }\end{array}$ & $\begin{array}{l}\text { Beliefs about the likely } \\
\text { effects of activities }\end{array}$ & $\begin{array}{l}\text { Environmental aspects } \\
\text { that assist or hamper } \\
\text { adherance }\end{array}$ \\
\hline $\begin{array}{l}\text { Theme I: Facilitators to } \\
\text { adherence }\end{array}$ & Inner strength & $\begin{array}{l}\text { Knowledge } \\
\text { Compliance } \\
\text { Fear }\end{array}$ & Improvement & $\begin{array}{l}\text { Support from service } \\
\text { providers } \\
\text { Family support } \\
\text { Enablers to access service }\end{array}$ \\
\hline $\begin{array}{l}\text { Theme 2: Barriers to } \\
\text { adherence }\end{array}$ & Emotional turmoil & & Not a cure & $\begin{array}{l}\text { Maintenance and effort } \\
\text { Lack of counselling } \\
\text { Physical symptoms } \\
\text { Aesthetics } \\
\text { Challenges to accessing } \\
\text { services }\end{array}$ \\
\hline
\end{tabular}

Participants reported that PGT impacted scar appearance and colour positively, but they found the slow process frustrating. They described components related to their motivation, resources and barriers which affected their volition and thus their varied levels of adherence to PGT. Two main themes emerged, i.e. facilitators of adherence to PGT and barriers in adherence to PGT. The categories under each of these themes were ordered under the four components that impact adherence behaviour according the the HAPA i.e. self-efficacy, risk awareness, outcome expectations, as well as barriers and resources as shown in Table II.

\section{Theme I: Facilitators of adherence to pressure garment therapy}

Inner strength

Participants described how being positive and their perceived self-efficacy in terms of following the PGT programme gave them emotional strength that helped them adhere to PGT.

Mandy: I just started changing the way I think...just be more positive... You have to learn to be okay with it, it's just not something that you 
can get used to easily [wearing PG] but eventually it becomes like part of your life...it's normal.

Sipho: I wanted to wear it, I wanted to heal properly... I just say okay, let me just wear it.

\section{Knowledge}

According to current study findings, education by therapists and contact with other burn survivors armed participants with knowledge and risk awareness of what to expect if the PG is not worn. This improved insight into the burn injury, its management and consequences and motivated adherence to PGT.

Phindi: ... you know the reason why you're wearing it and it's because you know and they explain it to you before they give it to you, they show you how to wear it... Like I know someone... she stopped coming here for her pressure garments... and now she's regretting that she stopped...

Sipho: I said "Hey am I gonna wear this like all the time?!" They say "Ja you must wear it all the time". And they show me some pictures there on the wall. "You see if you don't do this then it's gonna look like that. If you do this then it's gonna end up like this." So I said okay I want my skin to be soft ... 'cos they explained to me it's gonna take maybe two years for me to wear the tubigrips [PGs]

\section{Compliancy}

Most participants' adherence was based on their own motivation, self-efficacy and insight. Their decision to continue with PGT was an informed one based on knowledge of the options for scar management, but others appeared to rely on an external locus of control and explained that they just did what they were told to do.

Andiswa: I don't have a choice. So I have to do everything they [OT] say I must do...

Ann: And I just automatically did what they [OT] wanted me to...

\section{Fear}

Negative emotions further fuelled adherence for some participants. This included fear that not wearing the PGs would cause secondary complications, and that poor adherence might negatively affect access to services in future thus they adhered to PGT without question.

Andiswa: I will go there [OT] until they tell me to stop, it's for my health. What if something happens again then they not gonna take you maybe

Sipho: ... if I took them [PGs] off maybe... after an hour it starts to develop some... something like, er, pimples or something like that.

\section{Improvement in scars and other symptoms}

Participants described the progress in scar mobility and appearance as motivational. The perceived improvement encouraged them to continue to wear pressure garments in the expectation of further improvement.

Andiswa: ... when I checked it, it was coming flat and soft...I think it was helping me a lot...

Photographs of the scars provided visual proof of progress.

Mandy: If I look at pictures of when I just got out of hospital how it looked compared to now... big difference...

A reduction in symptoms like itching, pain and swelling further motivated adherence to PGT. One participant reported a positive effect on lymphoedema.

Mandy: ... if I didn't wear my pressure suit for a day, my body would start paining... it would itch and it would sort of make like... someone was stabbing me with needles.

Bongani: “. . . this leg. .. also even here in my knee, it was very big [swollen]... I see the difference [less swollen]."
Support from service providers

Participants found that physical and emotional support from service providers assisted in maintaining their motivation and self-efficacy, which buoyed their adherence.

Sipho: I was very impressed with the way they were helping me. I was very, very impressed... they were just talking about all things...now I'm not talking about the outside wounds but we were also emotionally affected but she will really; really help me because they were not only giving me the PGs. They were also advising me like you can still do things...things like that. They did give me that confidence.

Phindi: ... they're very understanding, more like they...they've been there. They know what you're going through even though they've never been burnt before but it's like they've been burnt themselves. And, um, they make you comfortable... you know when you're in my situation when you go for your appointment it will be, um, it will be, um, very difficult for you to, if you go there and find people who are not friendly and, um, people would be, like, you know, they' re friendly and they're not scared to touch you and they ask you every time you go there "How are you feeling?"... They care about what is going on with you and how you're feeling and the progress...

Mandy: They would let me know if it's looking better or not [the scars] so I guess they just give me feedback on something that I can't see really 'cos I see my scars every day.

Family support

The participants saw the emotional support and assistance they received from their families as essential resources in following the PGT programme. Family members encouraged them to wear the PGs and were instrumental in caring for the garments.

Fleur: And my husband encouraged me also to do it [wear the PG].

John: ...my mother always encouraged me. You must just do it [wear it], you must do it, you must do it... Oh, that was actually my mother who did that [washed the pressure garments]!

\section{Enablers to accessing the service}

Free health care, financial support and assistance with transport aided participants to keep appointments, an essential component of adhering to PGT.

Ann: ...it didn't cost me anything at the hospital...

Sipho: ...they give me that six-month temporary disability... it really helped me...l used it sometimes to get to the hospital and also for the food...

Family and employers were also reported as supportive in assisting participants to attend outpatient appointments.

John: ... my sister always dropped us off...

Phindi: I even told them [employer] on my interview... that if they take me, they know I have my appointments to attend. So they, they're fine with that. I just need to tell them in advance...I have the whole day off...

\section{Theme 2: 'Barriers in adherence to pressure garment therapy}

\section{Emotional turmoil}

Participants reported the emotional impact of the burn injury as being extensive. Having to deal with this affected their whole life, and the PGT programme seemed insignificant at times. They felt it was difficult to maintain motivation and self-efficacy for PGT in light of the negative emotions they had experienced.

Phindi:...emotionally you're not ok [crying]... if I can tell you what this... what this has done to me...I, l even thought of, um, suicide because of this... it was a mission for me to take a bath because I was...I don't know if I was scared to take my clothes off, so that I don't have to see my scars everyday. I had to buy new things now, most of the time because I couldn't wear the clothes that I used to wear... I used 
to cry whenever I'm in my wardrobe or looking for something to wear.

Mandy: There were times when I just wanted to give up on it [PG]. This whole... like I didn't want to care anymore...

\section{Not a cure}

The participants reported that the scars affected their self-esteem. It was difficult to accept the permanence of the scars and the effect they had on their bodies. They were aware that PGT was not a cure but an attempt to improve the appearance of the scars. The knowledge that there could never be complete recovery negatively affected their adherence.

Mandy: I feel like it's [PG] just trying to make a scar look nicer. A scar that's always going to be there, it's still a scar, it doesn't matter how it looks, it's still there, you know what I mean? It's like putting lipstick on a pig.

\section{Maintenance and effort}

The amount of effort involved in the ongoing maintenance (daily washing) of the pressure garments, and the assistance needed in donning and doffing was reported as barriers to motivation and long term adherence to PGT. Having to remove the garments for other interventions like scar massage was also reported as effortful and affected adherence to other treatment interventions.

Ann: ...it was a case of washing and... washing and sort of keeping up...

Mandy: It's not just the removing, it's just like... If I told you now go massage yourself three times a day would you be able to.... can't explain really...there is a lot of effort involved...

\section{Lack of Counselling}

The negative emotional experiences were exacerbated by what participants saw as a lack of emotional counselling services. They felt that no one was adequately dealing with the emotional consequences of their injury. Even though the support from occupational therapists and families were positive, counselling could have assisted them further with adherence to PGT.

Mandy: Um, I think people take...not for granted but little..., they don't really hear how much power, um, knowledge is or emotional support can be...just preparing people mentally, you know. Focus more on how people are feeling...I think their counselling needs to be better.

Phindi: You know if they maybe provided therapy or something it would make it much easier for you to deal with the 'new you' because you were not used to yourself being like that and now you're like that... The hospital needs to make sure that you are maybe transferred to, er, someone to talk to or someone that can help you, you know... once you, once you discharged at the hospital.

\section{Physical symptoms}

Side effects of PGT like discomfort and pain made adherence difficult. One participant felt that the tightness increased the need to urinate and another felt that it caused varicose veins.

Mandy:... it's so uncomfortable, it's so tight, it's so sweaty, it's so hot... and it's just not something that you can get used to easily wearing... it just caused me to pee a lot! ....Cos it's so tight you know!...Yor, and it like presses on your bladder...

Sipho: ...ja it was like very tight...it pains at times... it was a lot of itching... especially when it's cold and when it's very, very hot.

Ann: ...these stockings are bringing out veins in my legs...

\section{Aesthetics}

The female participants in particular were upset about receiving PGs made from beige instead of brown material which they indicated decreased their motivation to continue to wear the garments. They were adamant that the beige PGs were cosmetically displeasing and unfashionable, drew further unwanted attention and were an inappropriate colour for dark-skinned people.
Andiswa: ... the beige, the people they ask you what's wrong?! What's wrong and they will be like asking what's wrong... I think I don't like this colour really... Most of the people who are burnt are not like this colour [beige], most of the people who are burnt are like black people...if you wear a brown one and the brown one is very nice, I like the brown one...I think if you can try to get this material in brown it's fine.... At least when it's brown, people will think it's a vest or something...

Phindi: So I used that brown one, I liked that brown one because it doesn't get dirty so quickly and even though I put on that Haarmanse [traditional remedy], it doesn't show very quickly. ... the colour of the pressure garment [beige] you know it doesn't look good, it doesn't look right... it just spoils your whole outfit...

Mandy: Um, the colour of the pressure suits, it's disgusting...it's so unfashionable!... it also makes you not want to wear it, it doesn't go with anything you wear. Like they had a brown one for a while and that one was nice, was much nicer because it looked more like a clothes colour. Like if they gave like the normal brown, the other colour that goes with things then that would be fine. You'd want to wear it more.

\section{Challenges to accessing services}

Although a number of participants reported that access to services facilitated adherence to PGT, some reported the opposite. Their financial situation, transport challenges and other responsibilities sometimes prevented them from attending appointments. In these instances adherence was negatively affected by the lack of consistent support, and monitoring of garments and scars.

Sipho: Ja, sometimes I used to call them, hey I'm not gonna make it because I don't have money.

Ann: I find it very difficult to get to the hospital...I can't get high up with my body, er, onto the taxis...So I have to depend on somebody taking me.

Fleur: Like the last month I was supposed to be here but I couldn't because I had to take my child to the hospital.

\section{DISCUSSION}

Most of the study participants believed in their ability to adhere to the PGT programme, which resulted in five participants having good adherence and one having average adherence throughout the programme. In accordance with previous findings ${ }^{9,10}$ resources and barriers resulted in varied adherence to PGT. Similar to participants in the study by Ripper et $\mathrm{al}^{10}$ participants in this study indicated that their motivation was dependent on the expected outcome of a smoother, more pliant skin and enhanced by positive outcomes, such as seeing the scar improve and a decrease of other symptoms. Participants were aware of the risks and negative consequences of not adhering to PGT.

Successful outcomes of PGT are dependent on constant pressure $^{7}$. Partial adherence may result in poor outcomes, delayed scar maturation and extended therapy ${ }^{10,16}$. This might explain why some of the current participants wore the garments for longer than the two years recommended for optimal scar maturation.

Pressure garments are tight by nature and can cause unpleasant symptoms such as sweating, restricted mobility, pain, itchiness, swelling and blisters ${ }^{5.7,16}$. This in turn creates barriers to adherence as found in the current study, that of Ripper et al $^{10}$ and also identified in reviews of the literature ${ }^{5,7}$. While the tightness in itself is essential it must be ensured that garments fit properly and are adjusted regularly.

The effect of the burn injury, especially in the acute phase, taxed participants' self-efficacy and overshadowed their motivation and the importance of adherence to PGT. They described 'suicidal' and 'hopeless' feelings which negatively impacted their ability to plan, initiate and maintain health behaviour. A lack of emotional support and the insight that while the scars would improve in appearance they would always remain, further affected their self-efficacy negatively. The severe emotional effect of the scars is seen in comments like putting lipstick on a pig. These findings underscore the necessity 
of counselling - which Gilboa ${ }^{19}$ also advocated for, and according to our study participants - was lacking.

As also reported by Ripper et $\mathrm{al}^{10}$ another negative factor which affected adherence and is related to outcome expectations, was the slow change in scar appearance which participants found frustrating. This underscores the importance of feedback on scar appearance. The use of digital photography for feedback can play an important role in this regard ${ }^{10}$.

Previous studies ${ }^{9,10}$ reported that patients felt they received insufficient information regarding the intended effect of the garment or did not understand the information and that this resulted in poor adherence. Current study findings on information sharing varied. Some participants felt that training was provided and that they understood the reasons for wearing and how to manage PGT. These participants reported intrinsic motivation and insight into PGT. Others appeared to be motivated to adhere to PGT by risk awareness and fear of complications or negative consequences for future access to health care. Ripper et $\mathrm{al}^{10}$ also highlighted the fear of causing physical harm such as re-opening healed wounds in patients with burns, while the fear that not complying may negatively impact access to services in the future is seen as a rational act from the patient's point of view by Stewart et al .

Some participants appear to be motivated to adhere to PGT by external pressures and reported following therapists prescriptions without question. This needs attention if the burns unit is to provide a client-centred service. Even so participants were generally satisfied with the overall occupational therapy service and highlighted positive aspects such as the staff being friendly, compassionate and understanding. In accordance with findings from Hall ${ }^{20}$ current findings showed that education, feedback, practical and emotional support from occupational therapy service providers facilitated adherence to PGT.

Participants found the lighter colour garments undesirable and a barrier to adherence. This is supported by the findings of Stewart et $\mathrm{al}^{9}$ and literature reviews ${ }^{4,5}$. People connect the beige colour to illness/disability ${ }^{5}$. Stewart et al ${ }^{9}$ reported that beige PGs were issued without thought of patient's choice as therapists felt patients did not care about the colour of their pressure garments and limited availability of brown garments. This emphasises the importance of giving a patient choices in therapy to provide them with more control in a distressing situation, especially since darker colour material such as dark brown was available at the study setting.

As in the study by Ripper et $\mathrm{al}^{10}$ current study participants highlighted the effort of washing garments daily and in donning and doffing them. This was particularly so when the garments had to be removed for additional therapies more than once a day. Practical support from family members assisted in this regard ${ }^{10}$. Current study findings further concurred with findings by Ripper ${ }^{10}$ that families provided emotional support and motivation. On the other hand Stewart et $\mathrm{al}^{9}$ noted that patients reported a lack of encouragement, social and practical family support to wear their PGs.

The economic consequences of burn injuries can be significant ${ }^{21}$ and in this study a lack of finances was a barrier to adherence to PGT for some participants as the little income that is available is used for basic necessities such as food and clothing. The financial burdens experienced by some study participants were alleviated by a temporary disability grant.

\section{CONCLUSIONS}

The findings of this study are applicable to a South African context and indicate that factors other than financial constraints affecting adherence, are similar to those reported internationally. Participants found PGT to be a beneficial intervention that improved scar appearance. Even so participants struggled to adhere to the strenuous regime. Adherence to PGT relied on the interplay between barriers and facilitators, which were often interrelated, the patient's motivation and self- efficacy as well as the support they receive and whether the expected outcomes were met. The occupational therapist needs to be aware of all the interacting factors and should assist the patient to balance them in favour of the positive. Adherence is ultimately a personal decision that cannot be imposed.

\section{RECOMMENDATIONS FOR FURTHER STUDY AND CLINICAL PRACTICE}

A study to determine the relative importance of specific barriers and facilitators in relation to each other should be of assistance to guide service providers on where to focus their energies. There is a need to develop a reliable, valid, objective scar assessment tool for use in clinical practice and quantitative research. It is recommended that digital photos of scars are included in clinical records; the feasibility of using photos as a form of objective scar assessment should be explored. The use of black and brown material for pressure garments is recommended. Garments and colours must be chosen in conjunction with the patient. Counselling services must be included during the in-patient phase and in the community. Exploration of the feasibility of peer counselling is recommended.

\section{REFERENCES}

I. Macintyre L, Baird M. Pressure garments for use in the treatment of hypertrophic scars - an evaluation of current construction techniques in NHS hospitals. Burns, 2005; $3 \mathrm{I}(\mathrm{I})$ : I I- I4.

2. Yohannan SK, Ronda-Velez Y, Henriquez DA, Hunter H, Tufaro PA, Marren M, Sher M, Gorga DI, Yurt RW. Burn survivors' perceptions of rehabilitation. Burns, 2012; 38(8): II5I-II56.

3. Anzarut A, Olson J, Singh P, Rowe BH, Tredget EE. The effectiveness of pressure garment therapy for the prevention of abnormal scarring after burn injury: A meta-analysis. Journal of Plastic and Reconstructive \& Aesthetic Surgery, 2009; 62(I): 77-8.

4. Szabo MM, Urich MA, Duncan CL, Aballay AM. Patient adherence to burn care: A systematic review of the literature Burns, 2016; 42(3): 484-91.

5. Esselman PC, Thombs BD, Magyar-Russell G, Fauerbach JA. Burn rehabilitation: State of the science. Am J Phys Med Rehabil, 2006; 85(4): 383-4I3.

6. Bloemen MCT, Van der Veer WM, Ulrich MMW, Van Zuijlen PPM, Niessen FB, Middelkoop E. Prevention and curative management of hypertrophic scar formation. Burns, 2009; 35: 463-475.

7. Atiyeh BS, El Khatib AM, Dibo SA. Pressure Garment therapy of burn scars: evidence based efficacy. Annals of Burns and Fire Disasters, 20I3; XXVI(4): 205-2। 2.

8. Martin C, Bonas S, Shepherd L, Hedges E. The experience of scar management for adults with burns: An interpretative phenomenological analysis. Burns, 2016; 42(6): I3II-22.

9. Stewart R, Bhagwangee A, Mbakaza Y, Binase T. Pressure garment adherence in adult patients with burn injuries: An analysis of patient and clinician perceptions. American Journal of Occupational Therapy, 2000; 54(6): 598-606.

I0. Ripper S, Renneberg B, Landmann C, Weigel G, Germann G. Adherence to pressure garment therapy in adult burn patients. Burns, 2009; 35(5): 657-664.

I I. Bombaroa KM, Engrav LH, Carrougher G], Wiechman SA, Faucher L, Costa BA, Heimbachc DM, Rivara FP, Honari S. What is the prevalence of hypertrophic scarring following burns? Burns, 2003; 29(4): 299-302.

12. Gangemi EN, Gregori D, Berchialla P, Zingarelli E, Cairo M, Bollero D, Ganem J, Capocelli R, Cuccuru F, Cassano P, Risso D, Stella M. Epidemiology and Risk Factors for Pathologic Scarring After Burn Wounds. Arch Facial Plast Surg, 2008; 10(2): 93-102.

13. Stella M, Castagnoli C, Gangemi EN. Postburn Scars: An Update. The International Journal of Lower Extremity Wounds, 2008; 7(3): I 76-181.

14. Kornhaber R, Wilson A, Abu-Qamar MZ, McLean L. Adult burn survivors' personal experiences of rehabilitation: An integrative review. Burns, 2014; 40(I): 17-29.

15. Gauglitz GG. Management of keloids and hypertrophic scars: current and emerging options. Clinical, Cosmetic and Investigational Dermatology, 2013; 6: 103-I14.

16. Zurada JM, David AB, Kriegel MD, Davis C. Topical treatments for 
hypertrophic scars. Journal of the American Academy of Dermatology, 2006; 55(6): 1024-1031.

17. Schwarzer R. The Health Action Process Approach Model (HAPA) 20I I. <http://userpage.fu-berlin.de/health/hapa.htm> (22 October 2013).

18. Silverman, D. Doing qualitative research. 4th ed. London: Sage. 2013.

19. Gilboa D. Long-term psychosocial adjustment after burn injury. Burns, 200I; 27(4): 335-34I.

20. Hall E. Patient Satisfaction - Why Should We Care? American Academy of Emergency Medicine, 20 10; 17(6): 17.

21. Mistry RM, Pasisi L, Chong S, Stewart J, Wong RB. Socioeconomic deprivation in burns. Burns, 2010; (36): 403-408.

\section{Corresponding author}

Rogini Pillay

rogini.pillay@westerncape.gov.za 